Dear Author,

Please, note that changes made to the HTML content will be added to the article before publication, but are not reflected in this PDF.

Note also that this file should not be used for submitting corrections. 


\title{
Measurement of radiated underwater noise from a small research vessel in shallow water ${ }^{\text {ts }}$
}

\author{
Alex Brooker*, Victor Humphrey \\ Institute of Sound and Vibration Research, University of Southampton, Southampton, SO17 1BJ, UK
}

\section{A R T I C L E I N F O}

Article history:

Received 15 July 2015

Accepted 23 September 2015

Keywords:

Underwater radiated noise

SONIC project

Shipping noise

Propeller cavitation

\begin{abstract}
A B S T R A C T
The impact of man-made underwater noise on the marine environment has recently received increased attention from regulatory authorities, as evidenced by inclusion in the Marine Strategy Framework Directive (MSFD). Radiated underwater noise from ships, primarily resulting from propeller cavitation, has for many years been understood to be one of the major contributors to ambient ocean noise. Civilian research in this area has to date been relatively limited; standards covering the measurement of radiated noise from ships in deep water and associated data analysis procedures have only recently been published by national and international standards institutes. Less attention has so far been paid to the measurement of radiated noise from ships in shallow water environments. This is of interest as shallow water areas are more likely to be used by civilian researchers due to the logistical problems involved in undertaking trials in deep water. The issue of shipping noise has been identified as one requiring further research, indicated by the recent funding of several large collaborative projects by the EU (e.g. the SILENV, AQUO and SONIC projects). This paper presents ship radiated noise data measured using a three hydrophone array during a sea trial undertaken as part of the SONIC project.
\end{abstract}

(c) 2015 Published by Elsevier Ltd.

\section{Introduction}

Interest in the environmental impact of man-made underwater noise has increased considerably in the last two decades driven by a recognition of the increasing demands placed on the marine environment by, for example, the oil and gas, renewable energy and transport industries as well as an improving understanding of the sensitivity of marine fauna to underwater noise pollution. The inclusion of underwater noise as a key indicator of environmental status in the European Marine Strategy Framework Directive (MSFD) is testament to this interest.

Many studies have identified radiated underwater noise from merchant ships, predominantly resulting from propeller cavitation, as a major contributor to ambient noise levels in the oceans (e.g. Wenz (1962), Urick (1975) and Ross (2005)). While more recent studies have presented data indicating that shipping noise levels are increasing (Andrew et al., 2011; McDonald et al., 2006; McDonald et al., 2008). Consequently, any effort to determine the current status of the marine environment should consider shipping noise in detail.

(The research leading to these results has received funding from the European Union Seventh Framework Programme (FP7/2007-2013) under Grant agreement no. 314394).

* Corresponding author.

E-mail address: a.g.brooker@soton.ac.uk (A. Brooker).
The measurement of radiated noise from ships has historically been undertaken for military purposes using fixed noise ranges. More recently, researchers from both military (e.g. Wales and Heitmeyer (2002) and Scrimger and Heitmeyer (1991)) and civilian (e.g. McKenna et al. (2012), Merchant et al. (2014) and Hallett (2004)) backgrounds have used short or long term mobile deployed systems to measure shipping noise. While these have been a valuable contribution to the field, the lack of a standardised methodology for measurement, data analysis and reporting often hinders the comparison of different datasets.

The recent publication of internationally agreed standards (ANSI/ASA, 2009b; ISO, 2012) is the first step towards rectifying this issue and it is encouraging to see many researchers adopting these methods as closely as possible (Bahtiarian and Fischer, 2006; De Robertis et al. 2012; Peña et al., 2011). The fact that these researchers appear to have found it challenging to meet some of the requirements for the highest measurement precision methodology set out in the standards highlights the difficulty of undertaking these measurements in practice.

This paper concentrates on the results of full scale trials to measure radiated noise from a vessel following, as closely as possible, the methodology recommended in the standards cited above. As well as presenting some key results from the trials the methodology used is discussed and any departures from the standards are highlighted. 


\section{The SONIC project}

Funded under the European Union (EU) Seventh Framework Programme (FP7) the three year SONIC (Suppression Of underwater Noise Induced by Cavitation) project commenced in October 2012. It is a multinational collaborative project involving thirteen organisations from five European countries including universities, classification societies and naval, marine engineering and technical research institutes.

The funding of the project is in response to the requirement of the MSFD (European Parliament and the Council of the European Union, 2008) to achieve Good Environmental Status (GES) of EU marine waters by 2020. GES is defined in the MSFD by eleven qualitative descriptors, Descriptor 11 of which states that:

"Introduction of energy, including underwater noise, is at levels that do not adversely affect the marine environment".

The investigation of anthropogenic underwater noise is therefore a key element in achieving the goals of the MSFD. As discussed in the preceding section, shipping is a major contributor to the overall levels of noise in the oceans and therefore requires detailed consideration. The aim of the SONIC project is to investigate radiated noise from ships, primarily concentrating on underwater noise from propeller cavitation and to deliver tools to improve the measurement, mapping and mitigation of cavitation noise.

The project has three principal aspects. The first is to develop techniques for the accurate prediction of ship radiated noise levels from scale model tests. A number of approaches to improve the accuracy of these predictions are being explored. These include novel experimental and computational techniques for the measurement of cavitation noise in scale model facilities such as cavitation tunnels and towing tanks, taking into account the acoustically reverberant nature of these environments.

The second aspect of the project is to carry out measurements of radiated noise from a full scale ship at sea to provide data to validate the scale model predictions. The target vessel used for these full scale sea trials was the research vessel Princess Royal operated by the University of Newcastle. The first of these trials was undertaken in September 2013 and aimed to measure radiated noise using a deployed hydrophone array and similar methodology to recently published international standards.

The third aspect of the project focuses on mitigation. It aims to develop an underwater noise propagation model to estimate the "noise footprint" of an individual vessel and a "noise map" showing the contribution to the overall underwater noise levels in an area of ocean from multiple vessels transiting through the region over a period of time. Other than the noise propagation model itself, the inputs to this final stage include an empirical ship source level model that has been developed using a database of existing ship radiated noise level data compiled for the SONIC project. In addition, other mitigation measures relating to design and operation of propellers and the reduction of machinery noise are being investigated.

\section{ISO Publicly Available Specification for ship radiated noise measurements}

The American National Standards Institute (ANSI) standard (and the International Standards Organisation (ISO) Publicly Available Specification (PAS) subsequently based upon it) provides recommendations covering environmental conditions, suitable locations, specification and setup of measurement equipment, behaviour of the target vessel, post-processing of data and the metrics by which to report the data. It also provides three grades of measurement standard from Grade A, which provides the most stringent set of conditions, to Grade $C$ which allows for a reduced degree of measurement detail with corresponding increase in uncertainty. It is, therefore, a very comprehensive guide for researchers undertaking ship radiated noise measurements which takes into account a number of common issues.

Fig. 1 shows the recommended hydrophone setup geometry relative to the target vessel for Grade A measurements. The depths of the hydrophones are defined in relation to the distance at Closest Point of Approach (CPA) of the vessel and specified elevation angles of $15^{\circ}, 30^{\circ}$ and $45^{\circ}$. Assuming a vessel of less than $100 \mathrm{~m}$ in length (as is the case for the present study) the depth of the shallowest hydrophone, $\mathrm{d}_{1}$, is recommended as $27 \mathrm{~m}, d_{2}=58 \mathrm{~m}$ and $d_{3}=100 \mathrm{~m}$. This, however, is based on the trials being undertaken at a location that meets the minimum water depth requirements, that is the greater of $300 \mathrm{~m}$ or $3 \times$ ship length for Grade A measurements, $150 \mathrm{~m}$ or $1.5 \times$ ship length for Grade B measurements and $75 \mathrm{~m}$ or $1 \times$ ship length for Grade $C$ measurements.

The standard also covers the manoeuvring of the vessel during the measurements. The recommended test sequence is shown in Fig. 2 for the measurement of radiated noise from the starboard side of the vessel. The procedure requires the vessel to transit along a pre-determined path such that it passes the hydrophone array at the CPA point, perform a Williamson turn and return along the same track so that measurements of radiated noise from both port and starboard sides are made. The Data Window Length (DWL) is the distance between two points along the track either side of the CPA point defined by a $\pm 30^{\circ}$ angle about the hydrophone array position. The COMEX and FINEX points define the start and end of the run respectively with each point a distance $2 \times$ DWL either side of the CPA point. Between the COMEX and FINEX points the vessel must maintain constant speed and running conditions with minimal use of rudder to maintain course along the track.

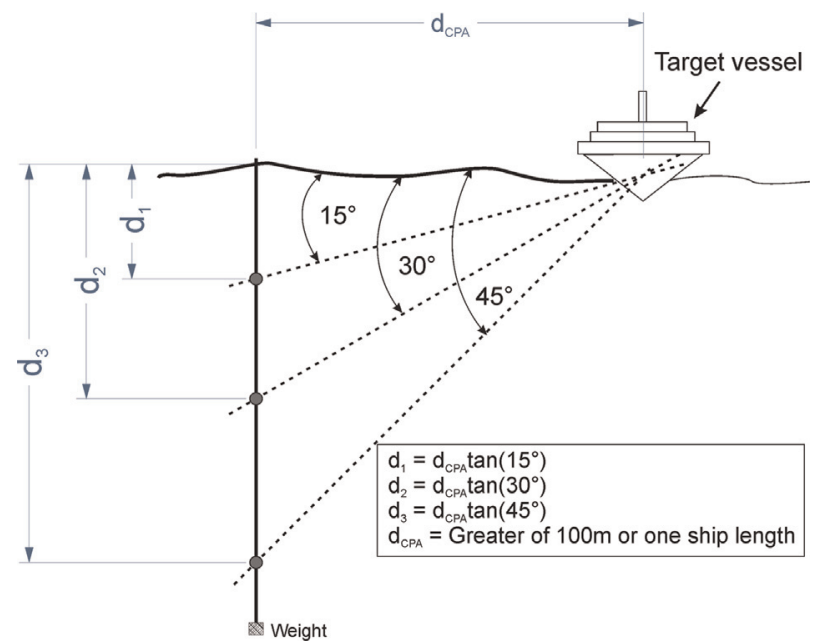

Fig. 1. Hydrophone array geometry recommended by the ANSI/ISO standards.

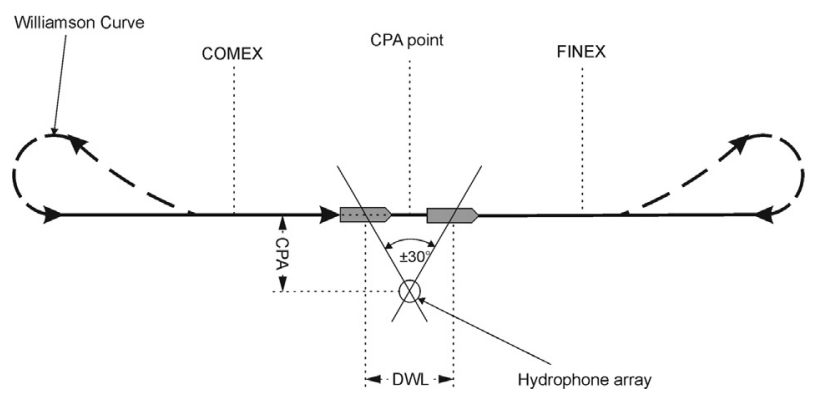

Fig. 2. ANSI/ISO recommended vessel test course (starboard side run). 


\section{SONIC full scale trials: measurement and data processing methodology}

\subsection{Measurement system}

During the SONIC full scale trials undertaken in September 2013 the University of Southampton deployed a vertical hydrophone array from a moored support vessel. The array consisted of three Reson TC4032 hydrophones and associated Reson cables, input modules and battery supplies. The acquisition system consisted of a National Instruments USB-6251 DAQ device sampling at $240 \mathrm{kHz}$ on each channel and proprietary acquisition software running on a standard laptop PC. A diagram of the basic setup is presented in Fig. 3.

The influence of surface wave motion on the array was mitigated by use of a spar buoy and by using an elastic tether to decouple the array from the movement of the support vessel.

The hydrophones were attached to a central rope using a custom built stainless steel protective cage and mounting setup. As well as preventing damage to the hydrophones during deployment and recovery, this provided a solid mounting on to the central rope to maintain the separation distance between hydrophones. In addition, the mounting fixed the hydrophones away from the central rope and cables, reducing unwanted system self-noise from turbulence around the array. The maximum hydrophone depth of the array was $50 \mathrm{~m}$, a departure from the specifications of the ANSI standard. The hydrophone depths within the $50 \mathrm{~m}$ maximum were fully adjustable in order to allow the deployment of all three hydrophones even in shallow water areas.

\subsection{Additional measurements}

Several other SONIC project partners were involved in the trial, each bringing significant additional measurement capabilities. In addition to the hydrophone array a differential GPS system was set upon the target vessel and the support vessel from which the hydrophone array was deployed. This GPS data was subsequently used during data post-processing to define the CPA distances and the data window used for analysis (discussed in Section 4.5).

In total, thirty transducers were installed on-board the target vessel measuring hull pressure pulses, engine and hull vibration, ultrasonic underwater noise, airborne noise in the engine room, propeller shaft speed and torque, engine power and a boroscope and several cameras to carry out detailed propeller cavitation observations. As well as providing detailed information of onboard noise and vibration generated by propeller cavitation and engines this also allowed records of the vessel operating

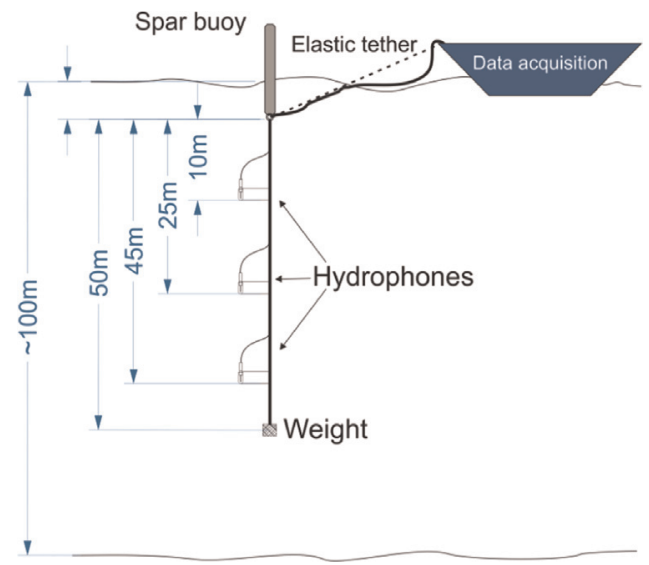

Fig. 3. University of Southampton hydrophone array setup. conditions during each run to be made in addition to the ship's own readouts.

In addition to the above, for each run a record was made of wind speed, wave height, vessel speed over ground (SOG) and speed through the water (STW), rudder angle and water depth from visual observations and the vessels own equipment.

\subsection{Target vessel and running conditions}

The target vessel used during the trials was the Princess Royal operated by the University of Newcastle, pictured in Fig. 4. Table 1 provides a specification of the vessel. In terms of access to the vessel, control over its operation during the trials and existing facilities to install on-board sensors, this vessel offered the ideal platform for the trials. The location of the trials could be dictated by the requirements of the measurements rather than the commitments or operating restrictions of the vessel. Additionally, vessel running conditions could be carefully controlled and logged and extensive on-board and off-board data to validate the scale model and numerical modelling results could be obtained. The disadvantage of the vessel is that in terms of hull design and size it is not particularly representative of the majority of the current merchant shipping fleet. The radiated noise data may, therefore, not be a good indicator of the typical levels of underwater noise generated by merchant ships.

In total 76 runs were carried out during the trial period. These included calibration and test runs as well as thirty eight runs following the ANSI recommended procedures to determine the

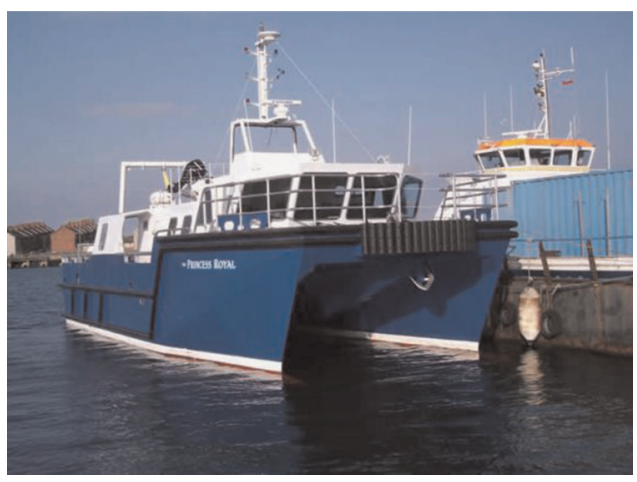

Fig. 4. The target vessel Princess Royal.

Table 1

Specification of the target vessel Princess Royal.

\begin{tabular}{ll}
\hline Classification & MCA Cat 2 \\
\hline Length & $18.9 \mathrm{~m}$ \\
Beam & $7.3 \mathrm{~m}$ \\
Design draft & At AP: $1.845 \mathrm{~m}$ \\
& At FP: $1.745 \mathrm{~m}$ \\
Displacement & 44 tonnes (approx.) \\
Payload & 5 tonnes \\
Maximum speed & 20 knots \\
Cruising speed & 15 knots \\
Engine power & $2 \times 602$ BHP \\
Propulsion & $2 \times 5-\mathrm{bladed}$, fixed pitch \\
& propellers \\
Propeller diameter & $0.75 \mathrm{~m}$ \\
Approximate source depth & $1.15 \mathrm{~m}$ \\
Max operational sea state & $4-5$ \\
Range & $400 \mathrm{Nautical}$ Miles \\
Cavitation inception point (engine rpm/ & $800 \mathrm{rpm} / 6.5 \mathrm{kn}$ \\
$\quad$ speed) & \\
Gearbox ratio & $1.75: 1$ \\
\hline
\end{tabular}


radiated noise from the vessel. The vessel operating conditions for each run were defined based on nominal engine revolutions per minute (rpm) values that could easily be controlled by the master of the vessel. During the initial phases of the trial, detailed cavitation observations were undertaken to determine the cavitation inception point for the vessel and also to record the extent of cavitation on the propeller for each running condition. Subsequently, several rpm values were chosen for the remainder of the trial that were representative of the development of cavitation on the propeller with increasing ship speed; these were 600, 700, 900,1200 and $1500 \mathrm{rpm}$, with additional runs at $2000 \mathrm{rpm}$ as time allowed. Two runs at each rpm value (one port side aspect and one starboard side aspect) have been used for the analysis presented in this paper.

\subsection{Trials location}

Three locations were selected for the trials, one preferred location and two backup locations, all off the north east coast of England. The backup locations were chosen to allow options for the measurements to continue in the event of poor weather conditions, albeit at a less ideal location to fulfil the aims of the trial. The preferred location was approximately $28 \mathrm{~km}$ from the coast in water depths of approximately $100 \mathrm{~m}$ with a seabed type consisting of soft mud. This location does not meet the minimum water depth requirements for the precision and engineering grades specified in the published standards (discussed in Section 3 ) and may therefore be considered a "shallow" water location. The other two locations were in shallower water and closer to shore in slightly more sheltered areas. All of the data presented in this paper are from measurements undertaken in the preferred location.

\subsection{Data analysis procedures}

Typically, data acquisition for each run was started when the target vessel team confirmed to the off-board measurement team via VHF radio that they had reached the COMEX position and stopped when the target vessel reached the FINEX position. The first stage of the analysis procedure was therefore to define the time window in the data corresponding to $\pm 30^{\circ}$ either side of CPA for each vessel run. This was achieved using GPS data to calculate the speed of the vessel, $v$ (in this case Speed Over Ground, SOG) to define the data window period, DWP:

$D W P=\frac{D W L}{v}$

The measurement system was synchronised to GPS time and hence the analysis window for each run was defined from Eq. (1).

The same analysis procedure was used for data recorded on each of the three hydrophones. The section of data corresponding to the DWP for each run was split into 1 second samples and a Hanning window applied to each sample with no overlap of windowed data. The Power Spectral Density (PSD) of each sample was then calculated to obtain the received levels (RL) at the hydrophones in terms of $\mathrm{dB}$ re $1 \mu \mathrm{Pa}^{2} / \mathrm{Hz}$. The PSD of the entire acquisition run was then calculated by power averaging across all $1 \mathrm{~s}$ samples in the DWP. One Third Octave (OTO) band levels were then calculated from the narrowband data by integration of the narrowband frequency points across each OTO band in accordance with the ANSI S1.11-2004 (ANSI/ASA, 2009a). Data were initially analysed over the frequency range from $10 \mathrm{~Hz}$ to $10 \mathrm{kHz}$.

In order to determine the radiated noise level (RNL) of the vessel in terms of $\mathrm{dB}$ re $1 \mu \mathrm{Pa}^{2} \mathrm{~m}^{2}$ a range correction must be applied. The correction applied to the data in this paper is of the form

$\mathrm{RNL}=R L+20 \log _{10}\left(\frac{r}{r_{\text {ref }}}\right)$,

where $R L$ is the received level, $r$ is the CPA range and $r_{r e f}$ is the reference range $(1 \mathrm{~m})$.

The RNL is also referred to as the dipole or "affected" source level. This terminology reflects the fact that this quantity has not been corrected for interference effects caused by the interaction of sound propagating along direct paths between the source and receiver and indirect paths that are reflected from the sea surface and seabed. The series of peaks and troughs in received level resulting from reflections from the sea surface are often referred to as the Lloyd's Mirror Interference Pattern (LMIP) and may be approximated by the expression (Ainslie, 2010)

LMIP $=10 \log _{10}\left(4 \sin ^{2}\left(\frac{k d_{s} d_{r}}{r}\right)\right)$,

where $k$ is the wavenumber, $d_{s}$ and $d_{r}$ the source and receiver depths respectively, and $r$ is the source-receiver range. Further discussion on the Lloyd's Mirror effect on surface ship radiated noise measurements can be found in Ainslie (2010) and de Jong (2009).

The ANSI and ISO standards require that data are presented as radiated noise levels and much of the data in the literature is also in this form. To allow comparison with the literature the range adjusted noise level data presented in this paper are presented as RNLs unless otherwise stated. However, as discussed by de Jong (2009), the analysis procedures described in the ANSI standard mitigate to some extent the influence of this interference. This is achieved using three approaches: averaging across multiple hydrophones, averaging across the DWP and presenting the data in terms of OTO bands rather than as narrowband data. Averaging the data across the DWP has only a marginal influence on the reduction of LM effects and is primarily aimed at ensuring a sufficiently long section of data is analysed. Multiple receiver averaging and OTO band analysis are the most effective methods for minimising the LM effects. To demonstrate this, Fig. 5 shows the results of averaging narrowband data across multiple receivers. Using Eq. (3) the LMIP is predicted for each of the three hydrophones based on the approximate trial geometry presented in Fig. 3 and using the given source depth for the Princess Royal target vessel of $1.15 \mathrm{~m}$. The varying locations in the frequency spectrum of the peaks and troughs demonstrate the dependence of the interference pattern on the trial geometry (i.e. CPA distance,

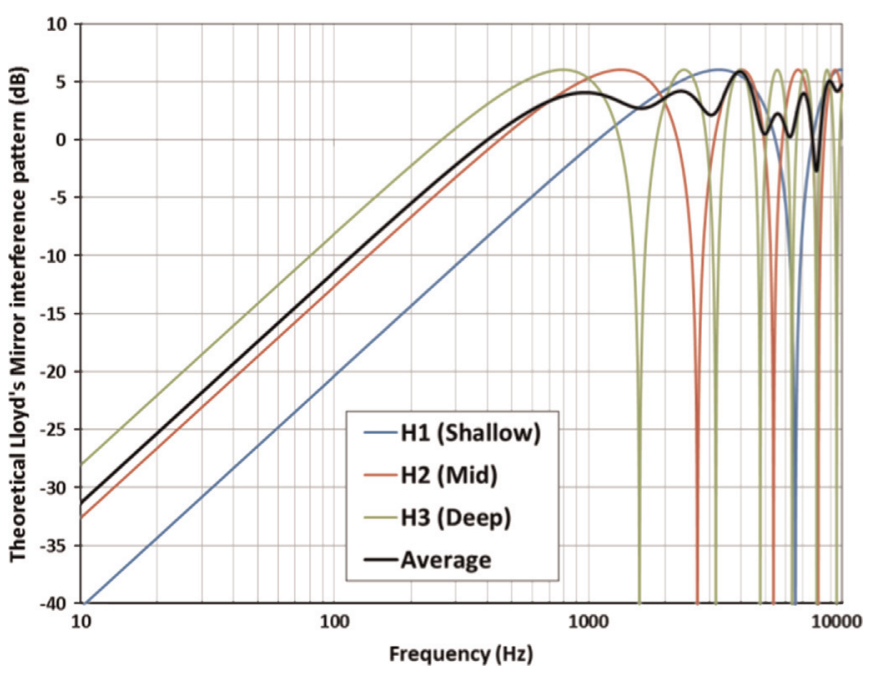

Fig. 5. Theoretical Lloyd's Mirror interference pattern. Horizontal CPA range $=100 \mathrm{~m}$, Source depth $=1.15 \mathrm{~m}, d_{1}=10, d_{2}=25 \mathrm{~m}$ and $d_{3}=45 \mathrm{~m}$. 


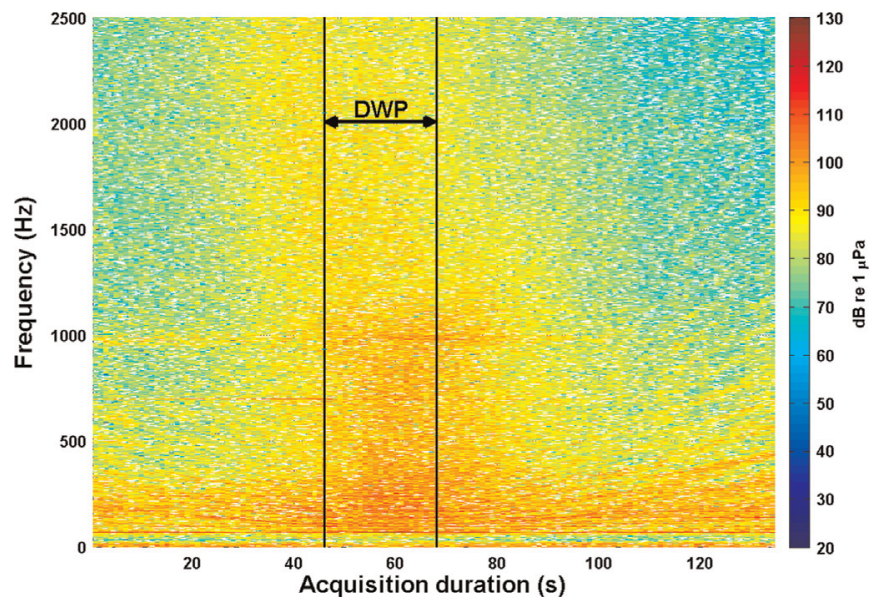

Fig. 6. Spectrogram of vessel radiated noise for a pass at $100 \mathrm{~m} \mathrm{CPA}$ at a speed of $11 \mathrm{kn}$.

source depth and receiver depth). The figure shows the result of averaging across three hydrophones deployed at difference depths which significantly mitigates the influence of the interference effects.

In practice the LMIP is not as clearly defined as in Fig. 5. Fig. 6 presents received levels of underwater noise during one pass of the target vessel at a nominal CPA range of $100 \mathrm{~m}$. The point at which the vessel passes the hydrophone location can clearly be identified by the increase in received underwater noise levels at around $60 \mathrm{~s}$ into the recording. The section of this file corresponding to the DWP that has been used for detailed analysis is also shown. While the interference pattern is not as clearly defined as the theoretical analysis presented in Fig. 5, the "U-shape" that can be seen in the figure clearly shows the LM effect and the changes in location of the peaks and troughs in the frequency spectrum as the vessel passes the receiver. However, it can be seen that the variation in pattern over the relatively narrow analysis window is small and hence averaging across the DWP does not significantly reduce the interference effects.

\section{Radiated noise data}

\subsection{Variation with receiver depth}

Fig. 7 presents the radiated noise levels measured on each of the three hydrophones in the vertical array during the SONIC trials averaged across 6 runs at the same vessel running condition $(1200 \mathrm{rpm})$. These data are dipole source levels, corrected for range assuming spherical spreading as in Eq. (2), using the slant ranges between the source and each receiver. Between approximately $100 \mathrm{~Hz}$ and $1 \mathrm{kHz}$, lower levels of radiated noise are measured on the shallowest hydrophone (blue line) than the deeper hydrophones This is expected as indicated by the LMIP in Fig. 5, showing that the propagation losses are greater for receivers deployed close to the sea surface. Above and below these frequencies the data do not show any depth dependence. As discussed in Section 5.2, below approximately $100 \mathrm{~Hz}$ the data are likely to be dominated by background noise and hence would not be expected to show a depth related effect. Furthermore, as demonstrated by the theoretical LMIP shown in Fig. 5, for the measurement geometry during the SONIC trials the influence of the LM effect is similar for each hydrophone above approximately $1 \mathrm{kHz}$ which is consistent with the measured data in Fig. 7.

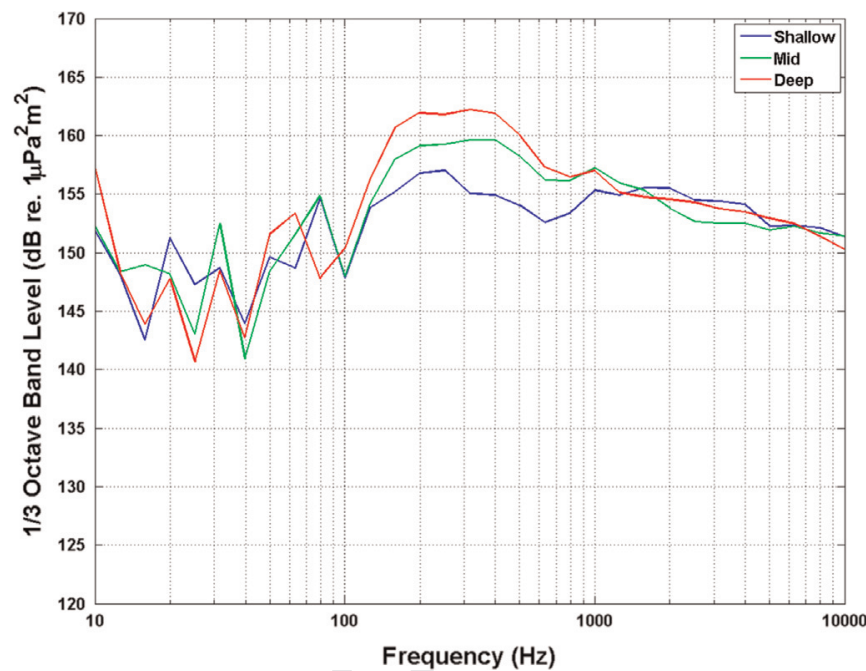

Fig. 7. OTO band "affected" (dipole) source levels for each hydrophone averaged across 6 runs at $1200 \mathrm{rpm}(\sim 9 \mathrm{kn})$.

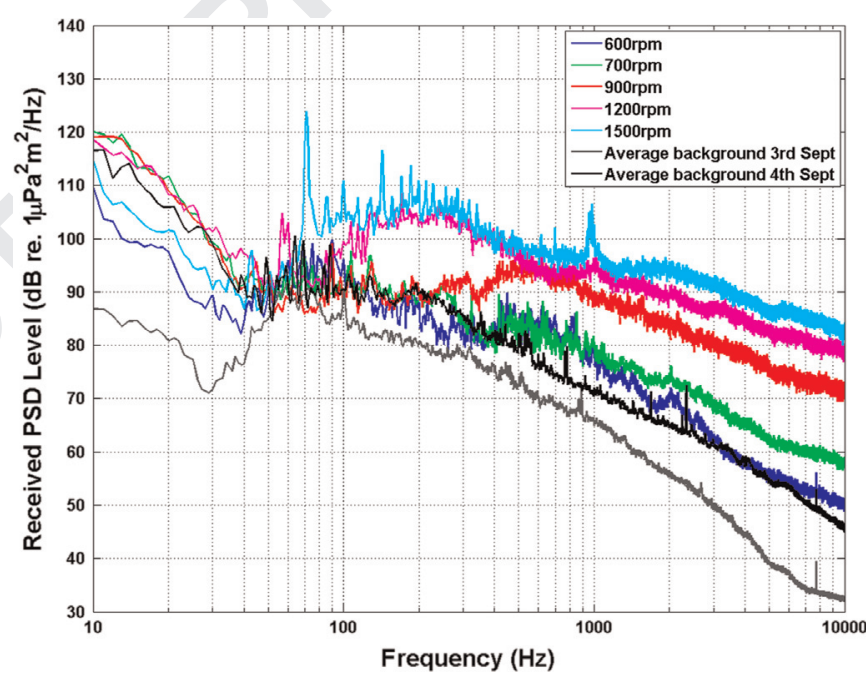

Fig. 8. Narrowband $(1 \mathrm{~Hz})$ received Power Spectral Density levels for various vessel speeds and measured background levels.

\subsection{Background noise}

The ISO and ANSI Standards also specify a correction required during data analysis to account for background noise recorded during the trial. This states that if spectral levels of radiated ship noise are less than $3 \mathrm{~dB}$ above background noise then the data are considered unusable. If the difference between the radiated noise level and the background noise level is between 3 and $10 \mathrm{~dB}$ then the background noise is subtracted (in terms of power) from the radiated ship noise data. If the difference is greater than $10 \mathrm{~dB}$ then no correction is required.

It should be noted that we use the term "background" noise here to refer to all extraneous noise that is not associated with the target vessel. While background noise generally refers to ambient noise in the environment that cannot be attributed to a particular source, here we are also referring to any noise associated with the measurement system. This includes sources such as cable strum, hydrodynamic noise resulting from flow around the hydrophones and hydrostatic pressure fluctuations resulting from vertical motion of the array in the water column due to surface waves.

Fig. 8 presents an example of received levels of noise for various ship speeds between $600 \mathrm{rpm}$ and $1500 \mathrm{rpm}$ measured on 4th 
September prior to any correction for background noise along with typical spectral levels of background noise on the same day. The background noise levels recorded on 4th September are very close to the levels recorded during the lower speed runs at 600 and $700 \mathrm{rpm}$ across most of the spectrum indicating that these data must be largely discarded. The higher speed run data indicate that large parts of the spectrum are not limited by background noise; however, even for the $1500 \mathrm{rpm}$ run the lower frequencies below approximately $70 \mathrm{~Hz}$ are likely to be dominated by background noise. This is in agreement with the data presented in Fig. 7.

Also shown in Fig. 8 is the typical spectral level of background noise measured on 3rd September. The lower levels of background noise recorded on the 3rd September suggest that the lower speed run data on this day of the trial could be reliably used as they are not dominated by background noise. However, it should be remembered that only snapshots of background noise data could be gathered at the beginning and end of each day of the trial. Noise associated with tidal flow or surface waves is likely to vary during the trial and during some periods could have been higher than when the background noise measurements were made. Radiated noise data measured during lower speed runs during this trial should therefore be treated with caution.

With this in mind, for the purpose of this paper, data at runs below $900 \mathrm{rpm}$ are presented for comparison purposes only and should not be used for detailed data interpretation. In addition, although Fig. 8 indicates that for the higher speed runs at $1500 \mathrm{rpm}$ the narrow peaks in the spectrum below $100 \mathrm{~Hz}$ are well above background noise, in general the data below this frequency for all runs are likely to be influenced by background noise. With the exception of the discussion in Section 5.3 below, the analysis in the remainder of this paper is limited to frequencies above $100 \mathrm{~Hz}$. All data subsequently presented in this paper have been corrected for background noise according to the published standards unless otherwise stated.

\subsection{Typical spectral characteristics of radiated noise}

Fig. 9 presents a narrowband Power Spectral Density (PSD) spectrum of measured radiated noise from a typical run at the $1500 \mathrm{rpm}$ vessel running condition. Data are presented for each of the three hydrophones in the array. The effect of the background noise limitation on the spectrum can be clearly seen below about $70 \mathrm{~Hz}$ where much of the spectral data has been discarded.

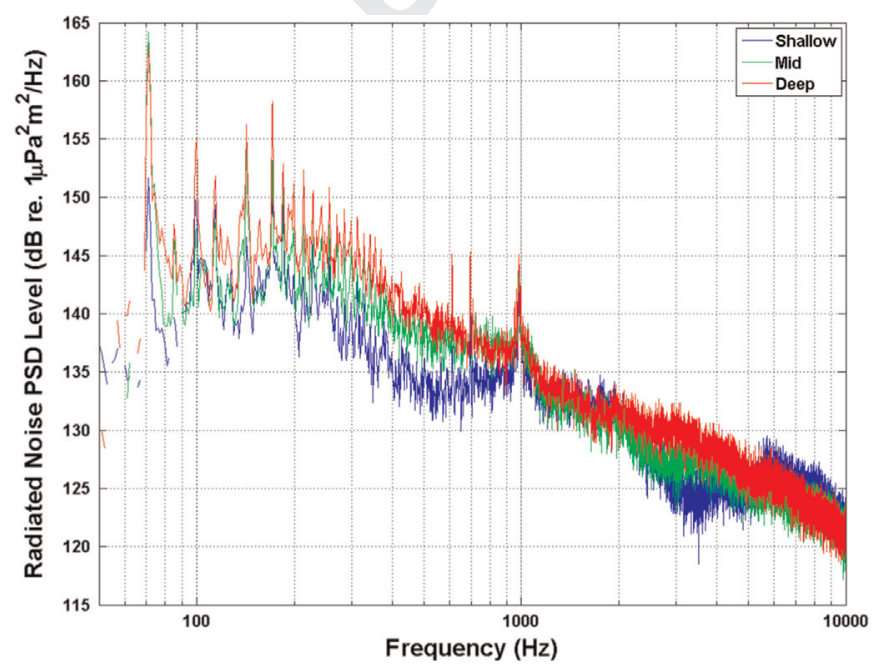

Fig. 9. "Affected" (dipole) source level in terms of narrowband Power Spectral Density for the target vessel at $1500 \mathrm{rpm}$, measured on each of the three hydrophones in the array.
This plot shows a number of important features of the radiated noise data. Firstly, the spectrum is characterised by a number of high amplitude narrow peaks in the frequency range from approximately 70 to $400 \mathrm{~Hz}$ with the highest level peak at approximately $70 \mathrm{~Hz}$. The target vessel has a gearbox ratio of 1.75 giving the propeller Revolutions Per Second $\left(R P S_{\text {prop }}\right)$ at an engine speed of $1500 \mathrm{rpm}$ as:

$R P S_{\text {prop }}=\frac{1500 / 1.75}{60}=14.3$

With a five bladed propeller this would give a blade passing frequency (BPF) of $71.4 \mathrm{~Hz}$, corresponding to the highest amplitude peak in the narrowband spectrum with lower level peaks indicating harmonics of the $\sim 71 \mathrm{~Hz}$ fundamental. The other lower amplitude peaks in the spectrum at frequencies greater than this fundamental occur at approximately $14 \mathrm{~Hz}$ intervals and are most likely a combination of higher harmonics relating to BPF, propeller shaft speed and engine firing rate.

\subsection{Variation of radiated noise levels with engine speed - spectral data}

Fig. 10 presents RNLs for a number of vessel speeds measured from starboard aspect. These OTO band spectra are the result of averaging across the three hydrophones in the array to give a single spectrum for each run. This plot clearly demonstrates the increase in radiated noise as the vessel speed increases. The nature of this increase in RNL is similar to that attributed by other researchers to propeller cavitation noise (e.g. Wittekind (2014)). At lower ship speeds it is first evident in the higher end of the frequency spectrum, in this case above approximately $1 \mathrm{kHz}$ when the speed is increased from 600 to $700 \mathrm{rpm}$. Clear increases are then seen down to approximately $400 \mathrm{~Hz}$ as the speed increases from 700 to $900 \mathrm{rpm}$, to approximately $100 \mathrm{~Hz}$ between 900 and $1200 \mathrm{rpm}$ and, as shown in Fig. 8, down to frequencies below $100 \mathrm{~Hz}$ from 1200 to $1500 \mathrm{rpm}$.

Fig. 11 presents the corresponding dataset from the port side aspect runs. The measured RNL and spectral characteristics are in general very similar to the starboard side runs.

In order to provide a comparison with what may be considered typical levels of underwater noise generated by a commercial ship the data may be compared to an adapted average ship source level model based on a large ensemble of measurements reported in Wales and Heitmeyer (2002). The model presented is in terms of

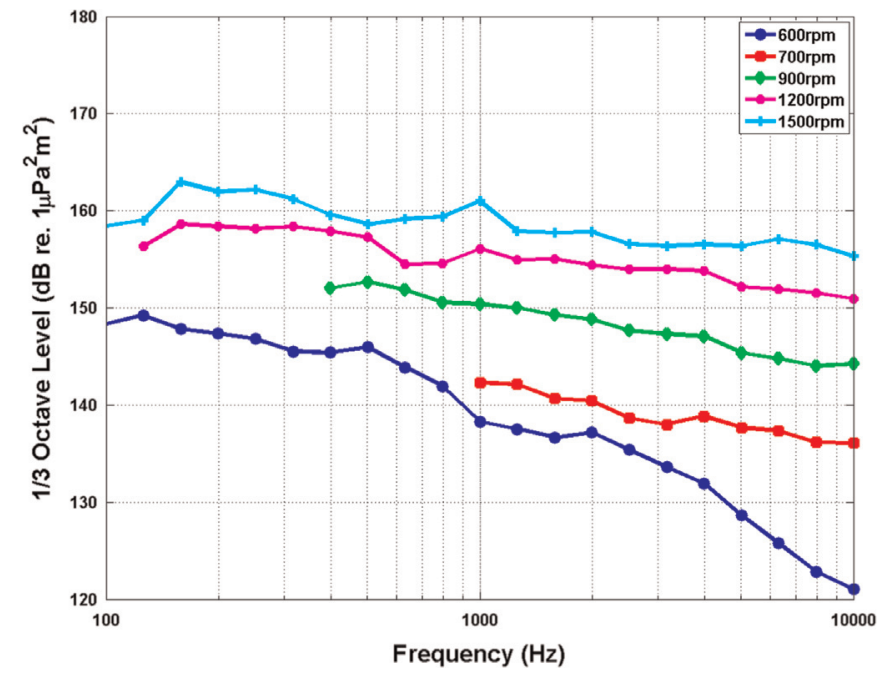

Fig. 10. Radiated noise at several engine speeds measured in starboard aspect (averaged over three hydrophones). 
the monopole source level for a ship. Therefore, in order to provide a valid comparison the dipole RNL data from the Princess Royal data must be converted to an approximate monopole source level. During the SONIC trials the measurement geometry (source depth and receiver depths) was not known in sufficient detail to reliably use the correction predicted by Eq. (3). However, a simplified approach based on Eq. (3) that may be applied to convert OTO band RNL data to a monopole Source Level $\left(S L_{m o n}\right)$ is provided by Robinson et al. (2011) as follows:

$S L_{m o n}=R N L+10 \log _{10}\left(\frac{1}{2}+\frac{1}{4 k^{2} d^{2} \sin ^{2} \theta}\right)$

where $k$ is the wavenumber, $d$ is the source depth and $\theta$ is the "look down" angle between the sea surface and hydrophone.

While application of this correction does not account for the complex interference pattern structure discussed in Section 4.5 these effects are minimised by the data analysis procedures discussed earlier. This correction therefore provides a suitable approximation to the monopole source level to allow a comparison with the Wales and Heitmeyer model.

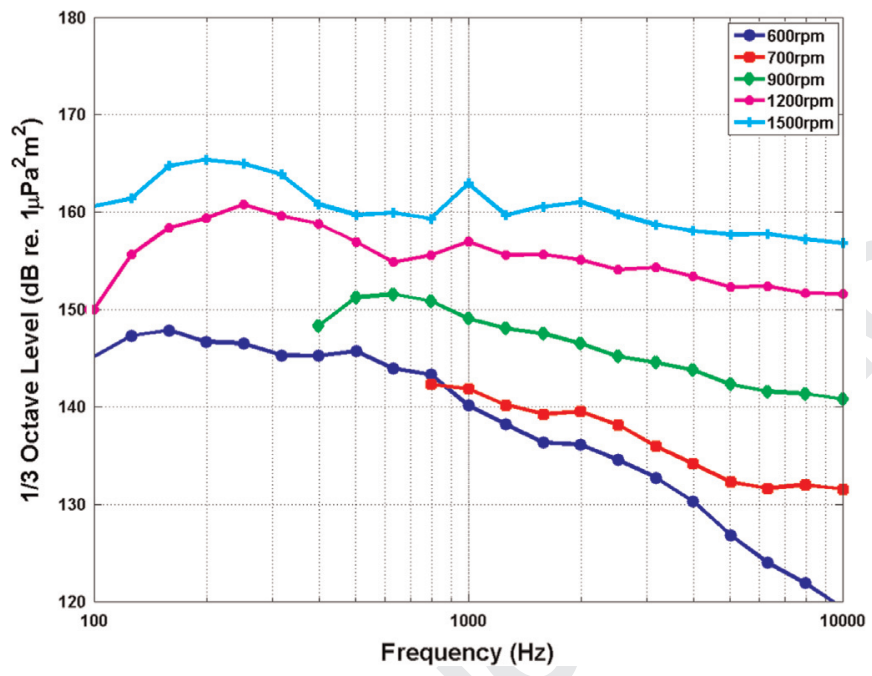

Fig. 11. Radiated noise at several engine speeds measured in port aspect (averaged over three hydrophones).

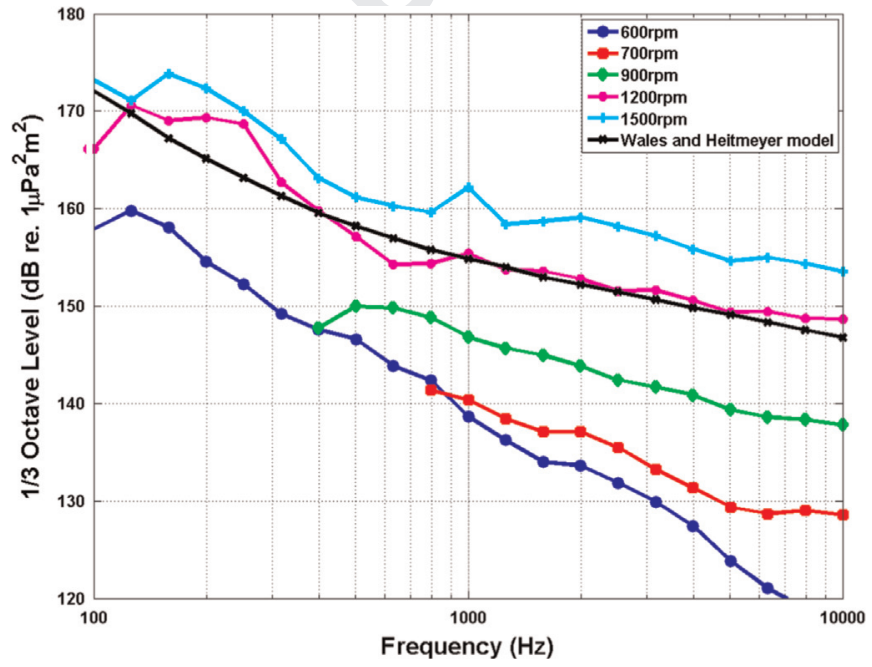

Fig. 12. Approximated monopole source levels at several engine speeds measured in port aspect (averaged over three hydrophones) in comparison with a source level model for a typical merchant ship.
Fig. 12 presents the OTO band monopole source levels for the port side runs along with the Wales and Heitmeyer model. The comparison indicates that over the frequency range from $10 \mathrm{~Hz}$ to $10 \mathrm{kHz}$ the radiated noise from the Princess Royal running at $1200 \mathrm{rpm}$ is similar to the typical underwater noise levels from a commercial ship operating at service speed. The service speed for the Princess Royal is $15 \mathrm{kn}$ which corresponds to engine speeds of $2000 \mathrm{rpm}$. These data therefore suggest that the target vessel generates relatively high levels of underwater noise when compared to a typical merchant vessel at normal operating conditions.

\subsection{Variation in radiated noise level with ship speed - overall broadband levels}

Previous studies have indicated that ship radiated noise levels are dependent on ship speed (e.g. Ross (1976), Trevarrow et al. (2008), Arveson and Vendittis (2000) and McKenna et al. (2013)) which is consistent with the findings of this study and with the theoretical link between propeller cavitation volume and radiated noise levels (e.g. Carlton (2007) and Gray and Greeley (1980)). A number of predictive models have been proposed that include a speed dependent term (e.g. Ross (1976) and Breeding et al. (1996)), however, these models are based on historical data much of which was measured during World War II. Comparison of these models to more recent data provides an indication of their relevance to modern ships.

Fig. 13 presents broadband RMS Radiated Noise Levels for the Princess Royal as a function of ship speed for nineteen runs at ship speeds of between 5 and $16 \mathrm{kn}$ calculated over the frequency range $100-10 \mathrm{kHz}$. Also shown in the figure is an historical speed dependence model (red dotted line) first proposed by Ross (1976) based on extensive data from radiated noise trials undertaken during World War II. This model is of the form:

$S L=A+c_{v} 10 \log _{10}\left(\frac{v}{v_{\text {ref }}}\right)$

where $A$ and $c_{v}$ are given constants, $v$ is the ship speed and $v_{\text {ref }}$ is a ship reference speed.

A least sum of squares (LSS) fit to the measured data shown in Fig. 13 from the present trial is also presented in figure. The fit to the data suggests that the radiated noise levels increased slightly quicker with speed than the Ross model predicts although overall the measured data agree very well with the model. Table 2

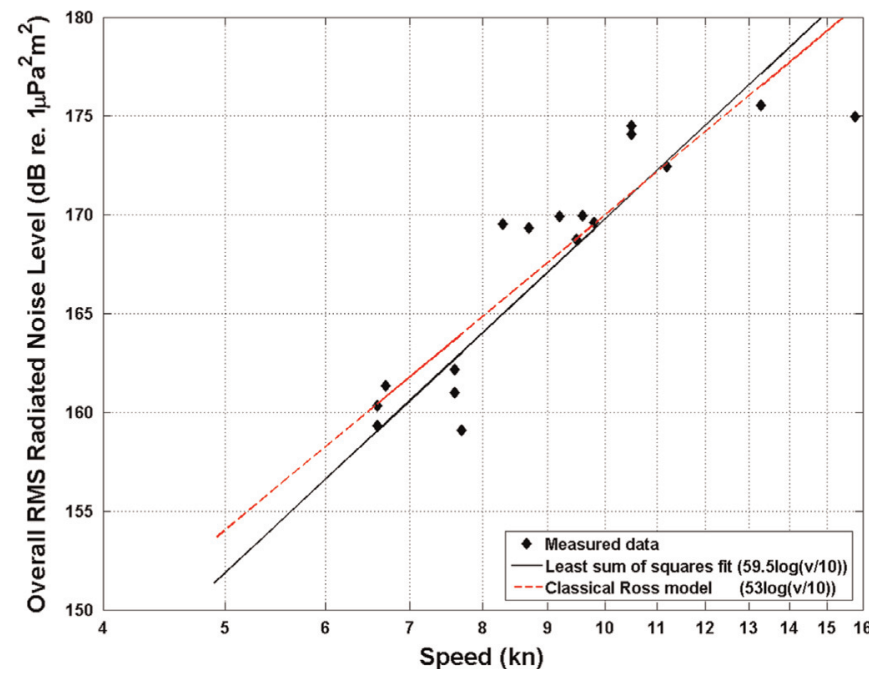

Fig. 13. RMS radiated noise level vs. vessel speed calculated over the full frequency range (100-10 kHz). Also shown is the classical model from Ross (1976) and a nonlinear least squares fit to the measured data. 
Table 2

Comparison of LSS fit statistics for the measured data to a classical speed dependence model

\begin{tabular}{llllll}
\hline Coefficient & $\begin{array}{l}\text { LSS fit } \\
\text { value }\end{array}$ & $\begin{array}{l}\text { Standard } \\
\text { error }\end{array}$ & $\begin{array}{l}\text { Lower 95\% } \\
\text { percentile }\end{array}$ & $\begin{array}{l}\text { Upper 95\% } \\
\text { percentile }\end{array}$ & $\begin{array}{l}\text { Ross } \\
\text { model } \\
\text { values }\end{array}$ \\
\hline$c_{V}$ & 59.5 & 5.8 & 47.3 & 71.7 & 53 \\
\hline
\end{tabular}

presents a summary of the fit statistics. This indicates that the speed dependence of the Ross model is well within the statistical limits of the fit. Due to the varying frequency ranges over which the data have been calculated, the spectral amplitudes are not discussed here.

\section{Discussion and conclusions}

The measurement of radiated noise from ships to meet the recently published international standards is a challenging undertaking. In the absence of a fixed noise range a vessel deployed mobile hydrophone array is the most viable alternative. The design and deployment methodology of such an array will inevitably have significant implications on the reliability and uncertainty of the measured data due to possible self-noise of the array. The data presented in this paper provide an indication of some of the practical issues encountered with the deployment of a typical array.

Undertaking these measurements in Northern European waters is also particularly demanding due to the relatively shallow water depths and the presence of other vessel traffic (and hence generally high ambient noise levels). However, as a region incorporating some of the busiest shipping lanes in the world it is important to investigate and develop tools and techniques to accurately measure or monitor shipping noise under these conditions. The SONIC project aims to contribute to this understanding using a range of approaches of which these full scale trials are one.

While improvements to array design and deployment would certainly enhance the quality of the measured data, the results presented in this paper show that the radiated noise characteristics of a vessel operating under trials conditions can be ascertained in some detail using a relatively simple hydrophone array. Comparison of radiated noise level data with a widely used ship source level model indicates that the target vessel used in this study is relatively noisy and generates slightly higher levels of underwater noise than might be expected from a merchant ship under normal operating conditions. A further comparison with another widely used model of variation in ship source level with speed has indicated that there is a clear positive correlation between radiated noise level and ship speed that is in close agreement with the model predictions.

\section{Acknowledgements}

The research leading to these results has received funding from the European Union Seventh Framework Programme (FP7/20072013) under grant agreement no. 314394

\section{References}

Ainslie, M., 2010. Principles of Sonar Performance Modelling. Springer, UK.

Andrew, R.K., Howe, B.M., Mercer, J.A., 2011. Long-time trends in ship traffic noise for four sites off the North American West Coast. J. Acoust. Soc. Am. 129 (2) 642-651.

ANSI/ASA, 2009a. ANSI S1.11: Specification for Octave-Band and Fractional-OctaveBand Analog and Digital Filters. Acoustical Society of America.

ANSI/ASA, 2009b. Quantities and Procedures for Description and Measurement of Underwater Sound from Ships- Part 1: General Requirements. American National Standards Institute/Acoustical Society of America.

Arveson, P.T., Vendittis, D.J., 2000. Radiated noise characteristics of a modern cargo ship. J. Acoust. Soc. Am. 107 (1), 118-129.

Bahtiarian, M., Fischer, R., 2006. Underwater radiated noise of the NOAA ship Oscar Dyson. Noise Control Eng. J. 54 (4), 224-235.

Breeding, J.E., Pflug, L.A., Bradley, E.L., Walrod, M.H., McBride, W., 1996. Research Ambient Noise Directionality (RANDI) 3.1: Physics Description. Naval Research Laboratory.

Carlton, J.S., 2007. 10 Propeller Noise. In: Carlton, J.S. (Ed.), Marine Propellers and Propulsion, Second Edition Butterworth-Heinemann, Oxford, Second ed.

de Jong, C., 2009. Characterisation of Ships as Sources of Underwater Noise. Rotterdamn, The Netherlands, NAG/DAGA International Conference on Acoustics.

De Robertis, A., Dorn, M., Ferno, A., Gerlotto, F., Handegard, N.O., Hawkins, A., Jones, E., Josse, E., Parrish, J.K., Simmonds, E.J., Wood, D., Wooder, B., 2012. Causes and consequences of fish reaction to fisheries research vessels Report from the Study Group on Fish Avoidance to research Vessels (SGFARV).

European Parliament and the Council of the European Union, 2008. Establishing framwork for community action in the field of marine environmental policy (Marine Strategy Framework Directive), in: European Parliament and the Council of the European Union (Ed.), Official Journal of the European Union.

Gray, L.M., Greeley, D.S., 1980. Source level models for propeller blade rate radiation for the worlds merchant fleet. J. Acoust. Soc. Am. 67 (2), 516-522.

Hallett, M.A., 2004. Characteristics of merchant ship acoustic signatures during port entry/exit. In: Proceedings of Annual Conference of the Australian Acoustica Society, Gold Coast, Australia.

ISO, 2012. Acoustics-Quantities and procedures for description and measurement of underwater sound from ships. General requirements for measurements in deep water. International Organization for Standardization (ISO).

McDonald, M.A., Hildebrand, J.A., Wiggins, S.M., 2006. Increases in deep ocean ambient noise in the Northeast Pacific west of San Nicolas Island, California. J. Acoust. Soc. Am. 120 (2), 711-718.

McDonald, M.A., Hildebrand, J.A., Wiggins, S.M., Ross, D., 2008. A 50 year comparison of ambient ocean noise near San Clemente Island: a bathymetrically complex coastal region off Southern California. J. Acoust. Soc. Am. 124 (4), 1985-1992.

McKenna, M.F., Ross, D., Wiggins, S.M., Hildebrand, J.A., 2012. Underwater radiated noise from modern commercial ships. J. Acoust. Soc. Am. 131 (1), 92-103.

McKenna, M.F., Wiggins, S.M., Hildebrand, J.A., 2013. Relationship between container ship underwater noise levels and ship design, operational and oceanographic conditions. Sci. Rep. 3, 1760.

Merchant, N.D., Pirotta, E., Barton, T.R., Thompson, P.M., 2014. Monitoring ship noise to assess the impact of coastal developments on marine mammals. Mar. Pollut. Bull. 78 (1-2), 85-95

Peña, H., Øvredal, J.T., Totland, B., Olav, N., Handegard, N.O., 2011. Underwater sound measurements from fishing vessel "Brennholm". Institute of Marine Research, Norway.

Robinson, S.P., Theobald, P.D., Hayman, G., Wang, L.S., Lepper, P.A., Humphrey, V. Mumford, S., 2011. Measurement of underwater noise arising from marine aggregate dredging operations Marine Aggregate Levy Sustainability Fund.

Ross, D., 1976. Mechanics of Underwater Noise. Pergamon Press, New York.

Ross, D., 2005. Ship sources of ambient noise. IEEE J. Ocean. Eng. 30 (2), 257-261.

Scrimger, P., Heitmeyer, R.M., 1991. Acoustic source-level measurements for a variety of merchant ships. J. Acoust. Soc. Am. 89 (2), 691-699.

Trevarrow, M.V., Vasiliev, B., Vagle, S., 2008. Directionality and maneuvering effects on a surface ship underwater acoustic signature. J. Acoust. Soc. Am. 124 (2) 767-778.

Urick, R.J., 1975. Principles of Underwater Sound. McGraw-Hill, New York.

Wales, S.C., Heitmeyer, R.M., 2002. An ensemble source spectra model for merchant ship-radiated noise. J. Acoust. Soc. Am. 111 (3), 1211.

Wenz, G.M., 1962. Acoustic ambient noise in the ocean: spectra and sources. J. Acoust. Soc. Am. 34 (12), 1936-1956.

Wittekind, D.K., 2014. A simple model for the underwater noise source level of ships. J. Ship Prod. Des. 30 (1), 7-14. 